\title{
LAS VENTAS DEL QUIJOTE: UN MICROCOSMOS ENCANTADO Y ENCANTADOR
}

\author{
ANTONIO BARBAGALLO
}

Stonehill College

Las ventas del Quijote han sido poco más que mencionadas por unos pocos críticos ${ }^{1}$, y totalmente pasadas por alto por el resto de ellos. «La tercera y cuarta parte del Primer Quijote -dice Mauricio Molho- son una sutil maraña de aventuras, que se distribuyen en torno a dos polos o lugares narrativos: Sierra Morena, donde se descubre a Cardenio y de donde parte Sancho para su embajada, y la Venta, recinto abierto de par en par, morada de todos y de nadie, en que el cura y el barbero montan con la complicidad de Dorotea una burla dramática de gran envergadura, la primera del Quijote: la historia de la princesa Micomicona»².

La poca mención de la venta es un hecho más que lógico y comprensible, cuando se trata de un elemento de una novela en la que aparecen tantos personajes dignos de ser estudiados, y donde suceden tantas cosas que reclaman no poca atención. Los seres vivos y sus obras vienen ganando la partida sobre un ente estático, pero creo que es preciso tratar de rescatar el protagonismo «venteril» tan injustamente desprestigiado hasta ahora. ¿Qué es entonces la venta en sí, más que una entidad costumbrista-realista, casi unamunescamente "intrahistórica», de cuya desaparición

\footnotetext{
${ }^{1}$ Aunque esto es una realidad ineludible, sin embargo es también verdad que algunos comentaristas han estudiado el tema de las ventas con cierta detención y seriedad, si bien enfocándolo de manera totalmente distinta entre sí. Cabe destacar EMILIO GONZÁLEZ LÓPEZ, "La evolución del arte cervantino y las ventas de El Quijote», Revista Hispánica Moderna, 34, 1968, pp. 302-312; LuIS AstranA MARín, Vida ejemplar y heroica de Miguel de Cervantes Saavedra. Madrid, Instituto Editorial REUS, 1953; JosÉ MARTíneZ ORTIZ, Las poblaciones manchegas del "Quijote». Ciudad Real, 1994.

${ }^{2}$ MAURICIO MolHo, Cervantes: raíces folklóricas. Madrid, Gredos, 1976, pp. 287-288.

AC. XXXVI (2004), 187-196
} 
se queja Azorín en su Castilla, y cuya ausencia canta melancólicamente don Antonio Machado? ¿Qué es, a nuestros ojos, más que otra de las tantas alucinaciones de don Quijote?

Bien pensado, la destartalada venta manchega es el lugar ideal, tanto como lo es real, donde desarrollar buena parte de la acción de una historia tan agitada y movida que requiere descansos. Cervantes necesita un marco natural donde encajar a tan variada multitud, y no puede elegir uno mejor que la «democratizadora» venta. Solamente el campo, el bosque y la sierra como fondo de la acción, harían de esta historia, estricta e inverosímilmente, otro libro de caballerías, o una novela pastoril. Por otro lado, desarrollar la acción en una ciudad podría hacer parecer la novela como una historia "burguesa», donde se imposibilita la aparición y mezcla de tan variada fauna humana. La venta, lugar por nada rebuscado, artificial o artificioso se convierte en el escenario más idóneo donde enmarcar de una vez a gentes de diversas condiciones, profesiones, creencias, edades y sexo, y donde ellos pueden no sólo contar sus hazañas pasadas, sino llevar a cabo otras. ¿Dónde podía haber metido Cervantes el cuento del cautivo, el del Curioso impertinente y otros, sino en la venta? No todo puede ocurrir en el campo o en casa de alguien. Este es el sitio público donde mejor se pueden empezar, desarrollar o cerrar círculos, y es justamente aquí donde don Quijote, por deseo propio y temor ajeno «legitimiza» su condición haciéndose armar y nombrar caballero andante. Además, para huir de la posibilidad de mostrar simplemente «tipos», o entes sociales, o casos clínicos, y para conseguir que todos los personajes se alejen de su propia condición social, separadora, tipificadora, y a la vez generalizadora, Cervantes hace que se encuentren todos dentro de la venta.

Si el autor, sea quien sea (ésta es una cuestión aparte), nos dice que don Quijote vio una venta, y que en su ilusión caballeresca la equivocó por castillo, nosotros nos vemos obligados a creer que tal lugar era una venta, ya que nuestra natural inclinación es la de no poner en duda la palabra del narrador. Él es el narrador-creador, y como tal nos está presentando su verdad. Sin embargo, esta realidad, que en definitiva es la nuestra, la que reconocemos, empieza a tomar matices nuevos, empieza a incorporar elementos que para nosotros son tan fantásticos como absurdos, pero que pertenecen al mundo real de don Quijote. De modo que se empiezan a fundir y a entretejer dos mundos, el mundo real de la venta, y el de don Quijote, que nosotros, por medio del narrador, consideramos fantástico e ilusivo. Es significativo que, después de haber presentado y calificado a las mujeres que estaban en el umbral: "Estaban acaso a la puerta dos mujeres mo- 
zas, destas que llaman del partido», Cervantes se avenga a la otra realidad impuesta por don Quijote, llegando a una especie de compromiso cuando dice: «llegó a la venta y a las damas». Esta oración es una metáfora o un símbolo de la incipiente independización y evolución de don Quijote. ¿No es la realidad de un loco tan «real» como la realidad de un cuerdo? Cervantes no se atreve a decir que don Quijote «llegó al castillo y a las damas», pero tampoco nos dice que «llegó a la venta y a las mozas». Las dos realidades acaban de fundirse, de amalgamarse en una para nosotros: la ambigua. La venta, por tanto, no sólo es castillo real en la mente de don Quijote, sino que, en cierto modo, se ha convertido en castillo verdadero. La realidad de un loco tiene el poder de alterar la verdadera realidad, ya que las prostitutas han cobrado la dignidad de damas que don Quijote les otorga, y visto que el ventero se ha convertido repentinamente en castellano con poderes para armar y nombrar caballeros. No somos testigos simplemente de las alucinaciones de un loco en cuanto a que tal loco come bacalao y pan malísimos creyendo que come truchas exquisitas, o en cuanto a que el silbato del castrador de puercos le produce música cortesana a sus oídos, sino testigos de la nueva realidad creada en estos seres, que se hacen partícipes del mundo de don Quijote. Sin perder la conciencia de su propia cruda realidad, las fulanas se sienten halagadas de ser tratadas como doncellas, con un lenguaje elegante, y de obtener el título de "doña». El ventero, por su parte, no sólo arma caballero andante a don Quijote, sino que no le cobra y le da consejos. Es en esta primera ventacastillo donde don Quijote necesita descansar y repostar energías la noche de su primera salida, pero, aunque es obvio que no es un Amadís o ninguno de los que no necesitan dormir ni comer, él no se da por enterado. A pesar de su hambre y cansancio y de las burlas de los huéspedes, don Quijote cree estar en un castillo, creencia reforzada por la serie de acontecimientos favorables: el nombramiento, el hospedaje gratuito y los varios consejos recibidos del castellano. Aquí, en esta venta y en estos consejos venteriles, se encuentra la génesis de Sancho. Este castillo, o sea, esta realidad de loco, viene de un «ideal» que significa "profundidad», no superficialidad sensual o realista - lo que Ortega llama «impresionismo»-, y por tanto es "lo que está más allá»3. El loco no inventa nada. La venta para don Quijote es un castillo, pero los castillos existen, por lo tanto, aunque la venta no es castillo para

3 José ORTEGa y GASSET, Meditaciones del "Quijote» e Ideas sobre la novela. Madrid, Ediciones de la Revista de Occidente, Colección El Arquero, octava edición, 1970, pp. 66-67. 
nosotros, bien podría serlo, y así, todo lo que en ella existe, podría bien ser una realidad existente en los castillos. ¿Por qué no pueden ser las prostitutas hermosas doncellas? ¿Por qué no puede ser el ventero un noble castellano? No hay más que considerarlos como tales y hacer que ellos mismos se consideren tales. ¿No son las ventas y todo su contenido otro elemento de transformación idealista cervantino?

A la segunda venta don Quijote llega con Sancho, hecho que no le impide tomar el humilde y pobre edificio por un noble castillo. Después de todo, si este loco ha impuesto al pobre rústico villano la nueva realidad de escudero, ¿cómo no va a transformar, al menos en su mente, la realidad de la venta? Vanas serán las palabras de Sancho, referentes a lo que se les presenta delante de los ojos; don Quijote, como caballero andante que se cree ser, no puede ser menos importante que el resto de su casta.

Las curas y el cuidado que la caritativa mujer del ventero dispensa al cuerpo molido de don Quijote son inmensamente agradecidos por el valiente manchego, quien, con palabras galantes, le dice que es hermosa, que no olvidará nunca sus servicios, y que, si no estuviera ya enamorado, se enamoraría de su hija, la doncella. Este trato desacostumbrado, junto a la explicación que Sancho da a Maritornes de lo que es un caballero aventurero, hacen que la realidad vulgar de estas pobres mujeres adquiera otras dimensiones. ¿Quién puede dudar de que la locura de don Quijote en cierto modo contagia e involucra a todo el mundo? Aunque no comprenden con exactitud lo que dice el dolorido caballero, sin embargo sus palabras les gustan y, sin saber cómo, las elevan a un plano superior de lo que es su escuálida realidad. Estas mujeres se sienten francamente bien con el trato y el lenguaje de don Quijote, quien "parecíales otro hombre de los que se usaban". Seguimos estando en una venta manchega, seguramente humilde y llena de pulgas, pero en el plano emotivo y psíquico, por poco tiempo don Quijote la ha convertido en castillo, y, según las normas caballerescas, es justo y normal que la hija del castellano se enamore del caballero. De aquí que los deseos de mantenerse fiel a un ideal, a esta idea de hermosura que se llama Dulcinea, están a punto de esfumarse. Es aquí, en esta venta, en su cama, donde don Quijote se imagina que esta doncella se le quiere entregar, y por mucho que quiera ser fiel a su amada, en la oscuridad de la noche y por equivocación, agarra a Maritornes, y teniéndola bien agarrada y sin querer soltarla, le habla de la imposibilidad de este amor, creyéndola ser la hija del castellano. Está claro que lo que hace y lo que dice don Quijote son dos cosas totalmente contradictorias, y que ni los dolores de su cuerpo apaleado, ni 
mucho menos el ideal de Dulcinea pueden apagar o disminuir su instinto carnal y su apetito lujurioso. Un análisis más a fondo se hará a su tiempo.

Sus palabras desencadenan los celos y los puñetazos del arriero, compañero "carnal», si no sentimental, de Maritornes, que comparte la habitación con don Quijote y con Sancho. Cuando todo ya vuelve a la calma y tranquilidad, el apasionado caballero atribuye los puñetazos a algún gran moro encantador que quería proteger la honra de la doncella, pero ¿a quién tocaba proteger la fidelidad, el ideal de don Quijote? ¿No habrá cobrado Sancho su ración de golpes como simbólico castigo por no haber estado alerta y no haber impedido lo que estaba a punto de convertirse en la traición del ideal? El escudero, al contrario de lo que opina Eduardo Urbina ${ }^{4}$, no debe y no quiere impedir la unión de don Quijote y Dulcinea, sino que debe y quiere simplemente aplazarla, prosiguiendo así indefinidamente la busqueda de la dama. También este tema será tratado en otro estudio. El hecho es que la traición del ideal de Dulcinea sería el final de la historia, y me parece que Cervantes "responsabiliza» a sus personajes de las cosas que consentirán que la historia se lleve a cabo. La oportunidad que don Quijote creía que se le presentaba, y su evidente necesidad biológica estaban a punto de matar un ideal, hecho del cual el caballero casi se avergüenza, ya que le impone el silencio a Sancho. Sin embargo, a su salida del castillo-venta o venta-castillo, los ojos de don Quijote no se despegan de la doncella, y el pobre caballero arranca profundos suspiros, que no se sabe si son de amor o de resignación y pena por la ocasión perdida.

Es en esta venta que el desdichado Sancho, después de haber padecido los efectos del bálsamo de Fierabrás, sufre un manteamiento espantoso, sin que su amo acuda a defenderlo. Para Sancho, esta es una venta tan real como inolvidable; para el todavía dolorido don Quijote, este es un castillo encantado, que por fin se convierte en venta cuando le piden el dinero del hospedaje. Pero, venta encantada, puesto que los que mantearon a Sancho, según don Quijote, eran encantadores, y él no pudo acudir en su ayuda por estar encantado. Como bien dice Ciriaco Morón Arroyo, «nuestra alma tiene un resorte contra el fracaso; y es la tendencia a culpar a los demás. El encantamiento cumple en el Quijote esa función de autoconsuelo que es el resorte más positivo de nuestra psique» ${ }^{5}$.

\footnotetext{
${ }^{4}$ EDUARDO URBINA, El sin par Sancho Panza: parodia y creación. Barcelona, Anthropos, 1991, pp. 88.

${ }^{5}$ Ciriaco Morón Arroyo, Nuevas meditaciones del "Quijote». Madrid, Gredos, 1976, p. 212
} 
La tercera y última venta que encontramos en la Primera Parte del Quijote es en realidad la segunda, la de Maritornes y del manteamiento, pero ahora adquiere especial importancia, ya que en esta ocasión Cervantes presenta el mayor número de elementos realista-costumbristas. Después de infinitas aventuras y vicisitudes, llegan don Quijote y Sancho con sus «supuestos» amigos, el cura y el barbero, y con Cardenio y Dorotea, la cual finge ser la princesa Micomicona. No corresponde aquí analizar los acontecimientos ni los personajes, ni los temas introducidos en esta venta, puesto que cada uno requiere y merece un estudio detallado, pero es importante señalar que es precisamente en la venta, en este marco realista, donde se introducen diversos y variados personajes, temas, y acontecimientos. Cervantes no quiere una infinitud de novelas para una infinitud de temas distintos; no. Quiere meter de todo en el Quijote, porque esta novela representa la vida en sí, y la vida tiene de todo. Es así que, bajo el mismo techo y de forma simultánea, encontramos a curas, barberos, caballeros y escuderos, comerciantes, soldados, arrieros, segadores, criados, hidalgos ricos, doncellas enamoradas, mujeres libertinas, cautivos, moras deseosas de ser cristianas, y, por supuesto, al ventero y la ventera, locos potenciales que creen al pie de la letra lo que se lee en los libros de caballerías. Es aquí, con este elemento costumbrista-realista de las reuniones "venteriles», donde alguien lee en voz alta para el goce y entretenimiento de todos los presentes, que Cervantes nos da idea del alcance que tenía la literatura de la época, en particular la de tema caballeresco. Con que una persona supiera leer era suficiente para que todo el mundo disfrutara de la lectura, una lectura que seguramente era seguida por el «comentario de texto». No hay más que oír las palabras del ventero, refiriéndose a esta literatura, para comprender el inmenso gusto que les proporciona: «A lo que yo entiendo, no hay mejor letrado en el mundo, y que tengo allí dos o tres dellos, con otros papeles, que verdaderamente me han dado la vida, no sólo a mí, sino a otros muchos» (I, XXXII). Por otra parte, las palabras del ventero reflejan cierta monotonía en la forma de vivir. Es casi seguro que durante largas temporadas del año las ventas estaban casi vacías, y es de imaginar que la vida en ellas no siempre era entretenida y placentera. La venta no es la casa de campo toscana donde se reúnen unos jóvenes de una misma clase social para escapar de la peste, y donde, para entretenerse, cada uno cuenta un cuento audaz y enredado, sino el lugar ideal donde introducir el panorama social español de la época. Es un centro "cultural» rural, en medio de algún camino, en que se reúnen en tertulia todos estos seres diversos que constituyen un verdadero microcosmos. 
Pero no olvidemos a don Quijote, quien en sueños - locos por cierto- lucha contra un gigante que resulta ser unos cueros de vino tinto, y en vela se queda colgado de una muñeca al querer besar la mano de la hermosa doncella. Una vez más Cervantes nos expone el problema de lo que es la verdadera realidad. No me refiero a lo que se percibe con los sentidos, especialmente la vista, sino al carácter de la gente, a los sentimientos y a todo lo que parece ser imperceptible. Habíamos visto que la ventera mostraba ser una persona caritativa y dulce, sin embargo los destrozos causados por la espada de don Quijote la vuelven tan furiosa que no parece la misma: «En mal punto y en hora menguada entró en mi casa este caballero andante, que nunca mis ojos le hubieran visto, que tan caro me cuesta [...] y por fin y remate de todo, romperme mis cueros y derramarme mi vino, que derramada le vea yo su sangre" (I, XXXV). Palabras muy fuertes éstas de la ventera, pero así es la verdadera realidad en el Quijote; no hay verdades absolutas, sino relativas. Casi todo es relativo. Cervantes aprovecha este estupendo marco como resorte y elemento unificador para dar unidad a una serie de acontecimientos que de otro modo, sin marco, quedarían sueltos. La venta, por lo tanto, adquiere plena significación como lugar donde se cierran y se enlazan varias historias que habían quedado abiertas e inconclusas, donde hay varios desenlaces favorables a sus protagonistas, y donde se desarrollan varios temas. Aquí concluye la aventura del barbero y del yelmo, acaba bien la historia amorosa de Cardenio y Luscinda, y la de Dorotea y don Fernando, se resuelve bien la aventura del cautivo y de su mora, como así finalizan otras historias que se habían ido introduciendo en la novela. No cabe duda que Cervantes, con todos estos personajes y sus historias, introduce y desarrolla el tema religioso, el tema de la guerra, el de los cautivos, el tema del amor - los diferentes tipos de amor-, sus ideas sobre el matrimonio, sobre los libros de caballerías, y otras cosas.

Si las ventas de la Primera Parte se presentaban ante don Quijote como castillos, al menos en un primer momento, y todo lo que ocurría en ellos le confirmaba cada vez más que era un gran caballero andante, las ventas de la Segunda Parte se le presentan desde el principio como verdaderas ventas, indicando así que hay un proceso opuesto en la percepción de la realidad por parte de don Quijote. Pero, sin entrar en lo que es la verdadera realidad en el Quijote, puesto que el tema requiere un estudio aparte (y que haremos para otra ocasión), conviene señalar que, por mucho que dijera que la venta era castillo, y que el trato recibido era el acostumbrado y merecido por los caballeros andantes, nuestro buen don Quijote no se lo creía de verdad, y no se lo 
habría creído de verdad ni aunque se lo hubiera jurado el mismo Amadís de Gaula. No sabemos que las alucinaciones locas, que cambian la realidad - bacalao y pan malolientes por truchas exquisitas; ventero por castellano; silbidos del porquero por música cortesana; etc.- no son más que «automentiras» hasta la Segunda Parte, cuando en el castillo de los duques el autor omnisciente nos revela que «aquel fue el primer día que de todo en todo conoció y creyó ser caballero andante verdadero, y no fantástico, viéndose tratar del mesmo modo que él había leído se trataban los tales caballeros en los pasados siglos» (II, XXXI). Ahora sí que sabe apreciar la diferencia entre lo bueno imaginado y lo bueno vivido. Todo esto requiere un estudio detallado, que hasta ahora nadie ha hecho, que no podemos hacer aquí.

En las ventas de la Segunda Parte no hay castellanos con hijas hermosas, ni cueros de vino vistos como gigantes, ni prostitutas vistas como doncellas, sino la plena y clara realidad de la época. Estas ventas reales muestran la evolución y desarrollo de los personajes en cuanto que la acción física y en cuanto que don Quijote parece estar cada vez más en contacto con la realidad.

La primera venta o mesón, que así es cómo también se llama en la Segunda Parte, se encuentra en el capítulo 25, y se presenta ante don Quijote como auténtico mesón. Aquí el buen caballero se entretiene con un hombre que lleva muchas armas, y que le cuenta la increíble y graciosa historia del porqué y del cómo se van a emplear las armas. Este hecho carece de importancia en este estudio, ya que no tiene relación directa con la venta, sin embargo, a través de él vemos que la venta sigue siendo el punto de encuentro de personas diferentes que transmiten, informan o comunican algo entre sí. Lo que resulta ser más importante e interesante para nosotros que analizamos la venta, es la introducción del retablo de Maese Pedro en cuanto a elemento costumbristarealista, puesto que es verdad que en aquella época y en otras existían retablos ambulantes que iban de venta en venta o de plaza en plaza, y en cuanto al ingenioso e inteligente recurso para enlazar las dos partes de la novela. En efecto, Maese Pedro no es otro que el galeote Ginés de Pasamonte, cuyo disfraz, aparte de proporcionarle protección, representa cierta evolución moral, siendo que ahora se gana la vida entreteniendo a la gente con su mono adivino y con su retablo. Los arrebatos de locura del primer Quijote, exteriorizados espontáneamente en forma de aventuras caballerescas sin apenas la menor provocación, ahora, en esta parte más racional y menos impulsiva, necesitan un fuerte estímulo generador. El retablo de Maese Pedro, que representa una historia caballeresca y amores contrastados, sirve, por tanto, de 
provocador de un arrebato de locura y da origen a una aventura caballeresca en la que Don Quijote actúa conforme a las normas de caballería, sin darse cuenta de que está luchando contra títeres.

Fue en la primera venta de la Primera Parte que Don Quijote asumió el cargo y la responsabilidad de ser caballero andante. Recordaremos todos que allí el ventero lo armó y nombró caballero, legitimando todas sus posteriores aventuras. En la segunda venta de la Segunda Parte, don Quijote asume otro cargo y otro papel, el de salvar todo lo que ha edificado hasta ahora, el de salvar su propio nombre, y por consecuencia toda la obra del historiador que escribía sus hazañas, la obra de Cide Hamete, la obra de Cervantes. En la venta o mesón el pobre caballero descubre que existe una "segunda parte» a su historia, una parte espuria que ridiculiza a él y a Sancho, y que no ha sido escrita por Cide Hamete Benengeli. Desde ahora en adelante, don Quijote, sin dejar su oficio de caballero andante, se empeñará en tratar de probar que esa segunda parte que ya existe es apócrifa, y que él es el verdadero don Quijote, amante de Dulcinea, hombre galante, discreto y bueno. Aquí, en la venta, nuestro hidalgo cambia sus planes para que no coincidan con los hechos descritos en esta parte falsa. Aquí mismo don Quijote muestra ser el verdadero, auténtico héroe, dando muestras de discreción y refinamiento, que corresponden a lo que se encontraba en la Primera Parte escrita por Cide Hamete, y no a esta "segunda parte» escrita por un aragonés. El plano realista de esta venta está reflejado en su mayor riqueza por estar situada más cerca del comercio marítimo.

A la vuelta de Barcelona, después de la derrota por mano del Caballero de la Blanca Luna, llegan nuestros héroes a la próxima venta, y es aquí que Sancho da muestras de discreción e inteligencia a unos labradores y al mismo don Quijote. Los labradores quedan asombrados y piensan que si el escudero es tan discreto, su amo debería ser doblemente discreto.

La capacidad inventiva de Cervantes llega a su culminación cuando nos demuestra que la "segunda parte» ya impresa es falsa, haciendo que don Quijote muestre su autenticidad. Se llega así a la última venta cuando amo y escudero están ya aproximándose a su aldea, y aquí Cervantes introduce a un personaje que don Quijote reconoce como personaje de la obra apócrifa. Este hombre, declarando que había estado con el don Quijote de la «segunda parte», el don Quijote grosero que no correspondía al héroe de la «primera parte» que él ya había leído, y reconociendo que nuestro don Quijote, por su discreción y modo de actuar, correspondía al "primero», y debía ser el verdadero don Quijote, confirma a 
todo el mundo lo que Cervantes se había propuesto probar: que la obra de Avellaneda era falsa y usurpadora.

Hemos visto que la diferencia entre las ventas de la Primera y Segunda Parte es sustancial. Mientras aquéllas servían como marco o escenario donde desarrollar temas e historias, y donde don Quijote transformaba la realidad, éstas sirven más bien para enlazar las dos partes de la obra, y como marco donde se introducen personajes que ayudan a destruir la parte apócrifa y a salvar el buen nombre de nuestros héroes. Las ventas en definitiva son un elemento de importancia decisiva al empezar, desarollar, terminar y salvar toda la obra.

«Las ventas tienen su significación en la literatura española y son inseparables del paisaje de España ${ }^{6}$ dice Azorín, pero opino que es justamente por ser inseparables del paisaje de España por lo que las ventas tienen su significación en la literatura española, y que Cervantes acertó de pleno en su elección de la venta como marco para desarrollar la mejor novela de nuestra literatura.

${ }^{6}$ Azorín, Castilla La ruta de don Quijote. Madrid, EDAF, 1984, p. 49. 